\title{
Clinical characteristics and treatment outcomes in a cohort of patients with pyogenic and amoebic liver abscess
}

\author{
Lorna Neill $^{1 *}$ DD, Frances Edwards ${ }^{1}$, Simon M. Collin², David Harrington', Dominic Wakerley' ${ }^{1}$ Guduru Gopal Rao ${ }^{3,4}$
} and Alastair C. McGregor ${ }^{1,3,4}$

\begin{abstract}
Background: We describe the clinical features of a cohort of patients with liver abscesses and investigate relationships between clinical, radiological and microbiological findings and mortality.

Methods: Retrospective review of pyogenic (PLA) or amoebic liver abscesses (ALA) diagnosed and treated at a major infectious diseases department in London over 9 years.

Results: One hundred forty-one patient records were identified; 132 (93.6\%) had PLA and 9 (6.4\%) ALA. No organism was identified in 38.6\% (51/132); a single bacterial species was isolated in 47.0\% (62/132) of PLA, $\geq 2$ in $14.4 \%$ (19/132). There was weak evidence of variation in abscess size by type of microorganism, with streptococcal PLA typically larger ( $p=0.03$ for Streptococcus milleri group, $p=0.05$ for non-milleri streptococci). Patients with ALA were younger (median 41, IQR 37-51 years) than those with PLA (median 68, IQR 50.5-78 years) $(p=0.003$ ) and all were male $(9 / 9,100 \%,(p=0.03))$, with a history of recent travel in the majority $(6 / 9,66.7 \%(p=0.003))$. Creactive protein was higher in ALA than in PLA $(p=0.06)$. In the entire cohort, loculation $(\mathrm{HR}=2.51(95 \% \mathrm{Cl}$ $1.00-6.32), p=0.04)$ and baseline ALP (HR $=4.78$ (95\% Cl 1.19-19.2) per $\log _{10}$ increase, $p=0.03$ ) were associated with mortality. 16S ribosomal RNA (rRNA) analysis was used in a subset of culture-negative cases and increased the diagnostic yield by $13 \%$.

Conclusions: Clinical or radiological features cannot be used to distinguish between PLA and ALA, or help identify the bacterial cause of PLA. However, ALA is more common in young, male patients with a history of travel. $16 \mathrm{~S}$ rRNA analysis of abscess fluid has a role in improving microbiological diagnosis in culture-negative cases.
\end{abstract}

Keywords: Liver abscess, Amoebic liver abscess, Pyogenic liver abscess, 165 ribosomal RNA, Risk factors, Treatment outcome, Hospital mortality

\section{Background}

The incidence of liver abscess, a rare but potentially lifethreatening infection, appears to be increasing worldwide [1-4]. The use of antibiotics, imaging and less invasive procedures for source control have improved treatment outcomes over the last century, but mortality remains high $[1,5,6]$ At present, there are no national

\footnotetext{
* Correspondence: Iorna.neill@nhs.net

${ }^{1}$ Department of Infectious Diseases and Tropical Medicine, London North West Healthcare NHS Trust, Northwick Park Hospital, Middlesex, Harrow HA1 3UJ, UK

Full list of author information is available at the end of the article
}

or international clinical guidelines, and limited evidence to guide decisions about care.

A wide variety of bacteria have been described as causes of pyogenic liver abscess (PLA), but published data on associations of bacterial species with clinical presentation, radiological findings and prognosis are sparse. Entamoeba histolytica, a protozoan parasite, is also a well-recognized non-bacterial cause of liver abscess. In Europe, cases of amoebic liver abscess (ALA) are rare and usually imported, whereas in some highly endemic areas ALA can be more common than PLA [7]. There is good evidence that ALA can be treated

(C) The Author(s). 2019 Open Access This article is distributed under the terms of the Creative Commons Attribution 4.0 International License (http://creativecommons.org/licenses/by/4.0/), which permits unrestricted use, distribution, and 
successfully with shorter courses of antimicrobial therapy than PLA, and that drainage is generally not required [8]. However, there is limited evidence as to how PLA and ALA can be distinguished clinically or radiologically.

In this study we describe a cohort of liver abscess patients treated at a large infectious diseases department over a 9-year period and report the clinical characteristics and treatment outcomes of PLA and ALA.

\section{Methods}

\section{Setting and patients}

We conducted a retrospective case note review of all adult liver abscess patients treated at our hospital (Northwick Park Hospital, Middlesex, UK) between May 2008 and June 2017. Patients presenting with liver abscess were identified using a prospectively recorded database of infectious disease inpatients, as well as a retrospective search of clinical coding data (search term "liver abscess", ICD 10 code $=$ K750). Data collected from the hospital electronic patient information systems included patient characteristics (age, sex, ethnicity), medical background and comorbidities, the results of standard biochemical and haematological tests on admission (full blood count, C-Reactive Protein (CRP), alanine transaminase (ALT), alkaline phosphatase (ALP) and bilirubin), the characteristics of the abscess (isolated microorganism(s) and resistance patterns, number of abscesses, maximum diameter and loculation), and treatment outcome (antibiotic use, use of aspiration, discharge, death).

\section{Management of liver abscess}

In the absence of consensus guidelines, patients with liver abscesses were investigated and managed at the discretion of the attending physician. Abscesses were identified by ultrasound or computed tomography. Samples submitted to the microbiology lab (abscess pus, blood cultures) were processed according to national guidelines (British Society of Antimicrobial Chemotherapy (BSAC), until February 2016, then European Committee on Antimicrobial Susceptibility Testing (EUCAST)) in a CPA (Clinical Pathology Accreditation) accredited laboratory. The choice of antimicrobial agents was guided by infection specialists. In a subset of cases, aspirates were sent for $16 \mathrm{~S}$ ribosomal RNA (rRNA) sequencing (Great Ormond Street Hospital, in-house assay). Amoebic serology was performed when there was clinical suspicion of $E$. histolytica infection (in-house immunofluorescent antibody test (IFAT) and Cellulose Acetate Precipitin (CAP), Department of Parasitology, Hospital for Tropical Diseases, London).

\section{Statistical analysis}

Characteristics of pyogenic and amoebic abscesses were compared using Fisher's exact and Kruskal-Wallis tests for categorical and continuous variables, respectively $(\alpha=0.05)$. Differences in clinical characteristics and treatment outcome (death within 30 days, and death within 6 months) by type of isolated microorganism were tested using a Wald-type test (F statistic) of Somers' D parameters for continuous variables (adjusted for withinpatient clustering) or Fisher's exact tests for categorical variables. Associations of type of microorganism with all-cause mortality (within 30 days and within 6 months of admission) were investigated by fitting random-effects parametric survival-time models with patient as the panel variable and standard errors adjusted for within-patient clustering. Risk factors for 6 month all-cause mortality were investigated using Cox regression models. Variables for which there was evidence $(p \leq 0.1)$ suggestive of an association in univariate models were carried forward to a multivariable model, from which variables were eliminated by mutual adjustment to obtain a final model of independently associated $(p \leq 0.05)$ risk factors.

\section{Results}

\section{Characteristics of PLA and ALA patients}

We identified 132 pyogenic liver abscess (PLA) and 9 amoebic liver abscess (ALA) admissions during the period May 2008 to June 2017 (Table 1). PLA patients were representative of the ethnically diverse local population: 47/132 (35.6\%) identified as "White (British/ other)"; 33/132 (25\%) as "Indian/Pakistani"; and 19/132 (14.4\%) as "Other Asian". All but one of the ALA patients was from an "Indian/Pakistani" $(5 / 9,55.6 \%)$ or "Other Asian" background (3/9, 33.3\%).

ALA patients were younger (median 41, IQR 37-51 years) than PLA patients (median 68, IQR 50.5-78 years) $(p=0.003)$, and all ALA patients were male compared with $63.6 \%(84 / 132)$ of PLA patients ( $p=$ 0.03). 66.7\% (6/9) of ALA patients had documentation of recent travel (<1 year) compared to only $21.1 \%$ $(23 / 132)$ of PLA patients $(p=0.003)$. Coexisting diabetes mellitus was recorded for $27.3 \%(36 / 132)$ of PLA and $33.3 \%(3 / 9)$ of ALA patients. Eighteen PLA patients (13.6\%) and none of the ALA patients were classed as immunocompromised in the preceding year. None of the patients were known to be HIV positive.

\section{Radiological characteristics of PLA and ALA}

There were no differences in the radiological characteristics of ALA compared with PLA: multiple abscesses, ALA 22.2\% (2/9), PLA 43.2\% (57/132), $p=0.30$; maximum diameter, ALA median $7.3 \mathrm{~cm}$ (IQR $5.8-8.8 \mathrm{~cm}$ ), 
Table 1 Characteristics of patients $(N=141)$ by type of liver abscess (pyogenic or amoebic)

\begin{tabular}{|c|c|c|c|}
\hline & & $\begin{array}{l}\text { Pyogenic } \\
(n=132)\end{array}$ & $\begin{array}{l}\text { Amoebic } \\
(n=9)\end{array}$ \\
\hline Sex & Male & $84(63.6 \%)$ & $9(100.0 \%)$ \\
\hline Age (years) & Median (IQR) & $68(51-78)$ & $41(37-51)$ \\
\hline \multirow[t]{6}{*}{ Ethnicity } & White (British or Other) & $47(35.6 \%)$ & $1(11.1 \%)$ \\
\hline & Indian/Pakistani & $33(25.0 \%)$ & $5(55.6 \%)$ \\
\hline & Asian & 19 (14.4\%) & $3(33.3 \%)$ \\
\hline & Other & 17 (12.9\%) & $0(0.0 \%)$ \\
\hline & Caribbean & $13(9.9 \%)$ & $0(0.0 \%)$ \\
\hline & African & $3(2.3 \%)$ & $1(11.1 \%)$ \\
\hline \multirow[t]{5}{*}{ Number of organisms ${ }^{a}$} & 0 & $51(38.6 \%)$ & - \\
\hline & 1 & $62(47.0 \%)$ & - \\
\hline & 2 & $9(6.8 \%)$ & - \\
\hline & 3 & $8(6.1 \%)$ & - \\
\hline & 4 & $2(1.5 \%)$ & \\
\hline Organism & None & $51(38.6 \%)$ & - \\
\hline \multirow[t]{6}{*}{ Grouped for analysis } & Enterobacteriaceae & $14(10.6 \%)$ & - \\
\hline & E. Coli & $21(15.9 \%)$ & \\
\hline & Klebsiella spp. & $21(15.9 \%)$ & \\
\hline & S. milleri group & 19 (14.4\%) & - \\
\hline & Other Strep spp. & $7(5.3 \%)$ & \\
\hline & Anaerobe & $16(12.1 \%)$ & - \\
\hline \multirow[t]{4}{*}{ Grouped as 'other' for analysis } & Enterococcus & $5(3.8 \%)$ & \\
\hline & Staphylococcus aureus & $1(0.8 \%)$ & - \\
\hline & Pseudomonas aeriginosa & $2(1.5 \%)$ & - \\
\hline & $\begin{array}{l}\text { Other (Anaeroglobus, Haemophilus, } \\
\text { Corynebacterium, Sutterella) }\end{array}$ & $5(3.8 \%)$ & - \\
\hline \multirow[t]{3}{*}{ Number of abscesses identified } & 1 & $75(56.8 \%)$ & $7(77.8 \%)$ \\
\hline & 2 & 19 (14.4\%) & $1(11.1 \%)$ \\
\hline & $\geq 3$ & $38(28.8 \%)$ & $1(11.1 \%)$ \\
\hline Maximum diameter (cm) & Median (IQR) & $\begin{array}{l}6.1(4.8-9.0) \\
n=118\end{array}$ & $\begin{array}{l}7.3(5.8-8.8) \\
n=8\end{array}$ \\
\hline Loculated & & $52(39.4 \%)$ & $1(11.1 \%)$ \\
\hline Antimicrobial resistance ${ }^{b}$ & & $45(34.1 \%)$ & - \\
\hline Abscess aspirated/drained & & 79 (59.9\%) & $6(66.7 \%)$ \\
\hline Diabetic & & $36(27.3 \%)$ & $3(33.3 \%)$ \\
\hline Recent travel (< 1 year) & & $23(21.1 \%)$ & $6(66.7 \%)$ \\
\hline $\begin{array}{l}\text { Immunosuppression (chemotherapy, steroids, immunotherapy or } \\
\text { combination in previous year) }\end{array}$ & & $18(13.6 \%)$ & $0(0.0 \%)$ \\
\hline Died within 30 days & & $7(5.3 \%)$ & $0(0.0 \%)$ \\
\hline Died within 6 months & & $20(15.2 \%)$ & $0(0.0 \%)$ \\
\hline
\end{tabular}

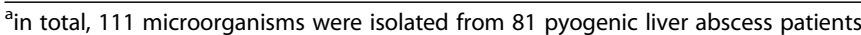

${ }^{\mathrm{b}}$ Resistance was detected to one or more antimicrobial agents in 45/132 patients and in 54/111 (48.7\%) of microorganisms

PLA $6.1 \mathrm{~cm} \quad(4.8-9.0 \mathrm{~cm}), \quad p=0.50$; loculation, ALA $11.1 \%(1 / 9)$, PLA $39.4 \%(52 / 132), p=0.15$, or position, ALA right sided abscess 77.8\% (7/9), PLA 68.6\% (81/ 118), $p=0.7$ (Additional file 1: Table S1).

\section{PLA microbiology}

Organisms were identified via culture from peripheral blood (33/132, 25\%) or from pus aspirated from the abscesses $(45 / 132,34 \%)$ or from both. $16 \mathrm{~S}$ rRNA gene 
sequencing was available from early 2015 , and was performed on 17 abscesses, giving a positive result in 14 cases; in 9/14 cases it was the only method by which an organism was identified (Additional file 1: Table S2). A single bacterial species was isolated in $47.0 \%(62 / 132)$ of PLA. Multiple pathogens were identified in 19/132 (14.4\%). In 51/132 (38.6\%), no microbiological cause was found. The most common bacteria identified were: Escherichia coli (15.9\%, 21/132); Klebsiella spp. (15.9\%, 21/132); and Streptococcus milleri group (14.4\%, 19/132) (Table 1).

\section{Clinical characteristics by type of microorganism}

There was weak evidence for overall variation in size $(p=0.04)$ and loculation $(p=0.09)$ of abscesses by type of microorganism (Table 2). Abscesses caused by streptococci (S. milleri group and non-milleri streptococci) tended to be larger than those caused by other microorganisms (Somers' D $p=0.03$ for S. milleri, $p=$ 0.05 for non-milleri streptococci). Abscesses with no isolated microorganism tended to be smaller $(p=0.04)$. There were no overall associations between specific microorganisms and baseline biochemical measurements (Table 2), but compared with all other microorganism: Enterobacteriaceae (including E. coli) and S. milleri were associated with lower ALT (Somers' D $p=0.03$ and $p=$ 0.05 , respectively), and Klebsiella with higher ALT $(p<$ 0.001 ). ALA tended to be associated with higher CRP $(p=0.06)$.

\section{Treatment}

$73.7 \%(87 / 118)$ of PLA had a diameter $\geq 5 \mathrm{~cm}$, compared with $87.5 \%(7 / 8)$ of ALA $(p=0.68)$. Overall, 76.3\% (71/ 93) of abscesses $\geq 5 \mathrm{~cm}$ were drained, compared with $25.0 \%(8 / 32)$ of abscesses $<5 \mathrm{~cm}$. There were $26 \mathrm{ab}-$ scesses $\geq 10 \mathrm{~cm}$ in diameter, including 1 amoebic abscess. In total, 78 (59.1\%) of PLA had aspiration/therapeutic drainage, and 9 (6.9\%) required a repeat aspiration/ drainage. Seven PLA patients (5.3\%) required open surgical drainage; 6/9 (66.7\%) ALA patients had an aspiration/drainage of their abscess, but none required further intervention. Length of stay was much shorter for ALA (median 7, IQR 6-9 days) than PLA patients (median 17, IQR 10-29 days) $(p=0.004)$. Antibiotic treatment in the PLA group was continued for a median of 53 days and needed changing at least once in $79.5 \%$ $(105 / 132)$ of patients, two or more times in $34.1 \%$ (45/ 132). Antimicrobial resistance was detected in $34.1 \%$ $(45 / 132)$ of patients, and in $48.7 \%(54 / 111)$ of isolated microorganisms, almost exclusively in enterobacteriaceae $(74.3 \%(26 / 35))$ and Klebsiella $(71.4 \%(15 / 21))$. Resistance in the PLA group to the most commonly used first line empiric antibiotics; co-amoxiclav, piperacillin/ tazobactam and metronidazole was $12.1 \%$ (16/132), 1.5\% $(2 / 132)$ and $0 \%$ respectively (Table 2$)$.

\section{Associations of type of microorganism and other factors with death}

There were no deaths in the ALA group, compared to $5.3 \%$ (7/132) 30-day mortality and $15.2 \%$ (20/132) 6month mortality in the PLA group. Two of the seven 30-day deaths and 4/20 6-month deaths were patients with biliary malignancy. There were no associations between type of microorganism and all-cause mortality within 30 days or 6 months (Additional file 1: Table S3). In univariate analyses, only age was associated with death $<6$ months (hazard ratio (HR) $=1.05$ (95\% CI 1.02, 1.09) per year increase, $p=0.003)$. Loculation, baseline anaemia $(\mathrm{Hb}<110 \mathrm{~g} / \mathrm{L})$, baseline ALP, and immunosuppression (chemotherapy, steroids, immunotherapy) met the criteria $(p \leq 0.1)$ for evaluation by multivariable analysis. Loculation ( $\mathrm{HR}=2.51$ (95\% CI 1.00, 6.32), $p=0.04$ ) and baseline ALP (HR $=4.78$ (95\% CI 1.19, 19.2) per $\log _{10}$, i.e. tenfold, increase, $p=0.03$ ) (Additional file 1 : Table S4) were independently associated with mortality when mutually adjusted.

\section{Discussion}

In our cohort of patients with liver abscess we found no large differences in clinical parameters between pyogenic liver abscess (PLA) and amoebic liver abscess (ALA), other than weak evidence of higher baseline C-Reactive Protein (CRP) for ALA compared with PLA. PLA patients had a 6-month mortality of $15.2 \%$ (20/132), whereas no ALA patients died. We found that streptococci were associated with larger abscesses than other bacteria. Baseline ALP and loculation, but not type of microorganism, were associated with increased risk of 6month all-cause mortality in the PLA group.

Previous studies comparing pyogenic and amoebic abscesses have attempted to identify features that distinguish the two, other than travel history [7, 9-12]. Many reports have shown a preponderance of ALA in male patients, who also tend to be younger than patients with PLA [4, 6, 9-18]. Others have documented differences in shape, position and echogenicity on ultrasonography that suggest ALA over PLA [10, 12, 19, 20]. Our results are consistent with the epidemiology described in these earlier papers, as all of our ALA patients were male and had a median age 30 years younger than the PLA patient group. As in other studies, all 9 ALAs in our cohort involved the right lobe ( 2 also involved the left). We also found that CRP was higher in ALA than in PLA, although this result is unlikely to assist in differentiating these entities.

Half $(47 \%)$ of PLAs in our study were monomicrobial, and the most common bacterial isolates (found in 


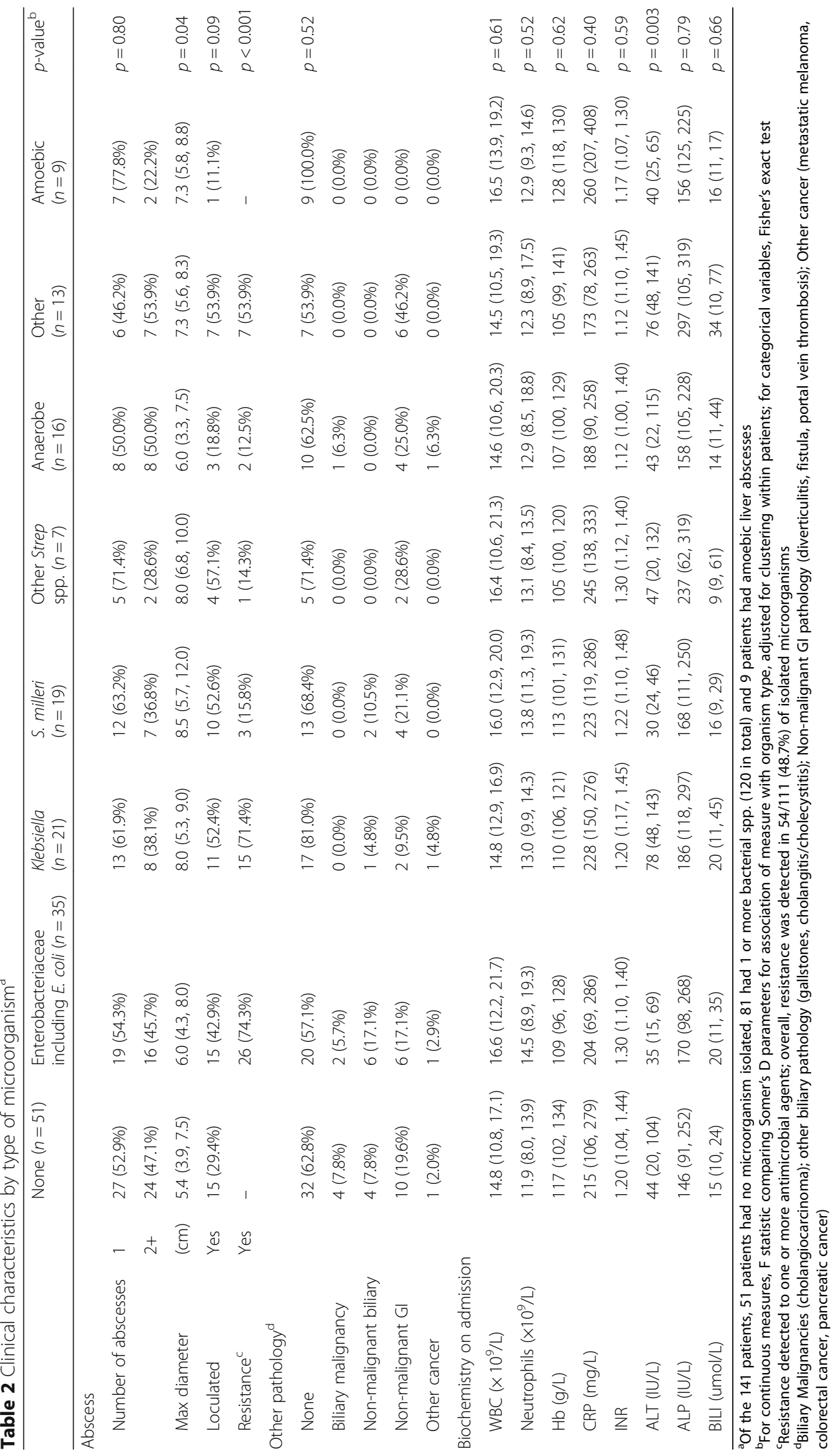


roughly equal proportions) were $E$. coli, S. milleri group and Klebsiella species, consistent with results from a number of other studies [1, 16, 17, 21, 22]. Culture of fluid obtained by cyst aspiration provided a microbiological diagnosis in 34\% of cases, whereas blood culture was only positive in $25 \%$. Given the importance of Enterobacteriaceae as etiologic agents in PLA, and the associated problems of antibiotic resistance, aspiration for diagnostic purposes would appear to be a crucial tool in optimising management. There is also likely to be a role for routine testing of culture-negative aspirates with newer molecular techniques such as PCR amplification and sequencing of the 16S ribosomal RNA (rRNA) gene. This has been shown to be more sensitive than traditional culture methods $[23,24]$, particularly when antibiotics have been administered [25]. In our cohort, $16 \mathrm{~S}$ rRNA PCR was the only method resulting in a microbiological diagnosis in $9 / 14(64.2 \%)$ cases in which it was used. Overall, this technique increased pathogen detection by $13 \%$ and only $3 / 17$ (17.6\%) samples were negative. Although $16 \mathrm{~S}$ rRNA analysis does not provide antibiotic susceptibility data, the risk of resistance can be inferred from the identity of the pathogen. Associations between radiological features and type of organism were weak, although we did find that abscesses caused by streptococci tended to be larger than abscesses caused by other bacterial species.

Biliary abnormalities are estimated to be responsible for $30-50 \%$ of cases of PLA and are more common than those related to portal pyaemia, or haematogenous or direct spread from an adjacent viscus [5, 12, 26-28]. In our cohort, a biliary source was demonstrated in only 18/132 (13.6\%). The reason biliary sources were less common in our cohort than in other series is not clear. Diabetes appears to be a major risk factor for developing PLA, and is associated with severe disease [29-31]. About $30 \%$ of our patients with both ALA and PLA were diabetic and it is possible that cases in this group are over-represented in our cohort. The source of infection remains unclear in significant number of PLAs [1, $15,16]$ and we were unable to demonstrate a source of infection in almost $40 \%$. A source of particular concern is GI malignancy, as these can easily be missed on initial imaging and reports have documented occult colonic malignancies in approximately $24 \%$ of cryptogenic PLAs, suggesting that luminal imaging or colonoscopy should be seriously considered in individuals with PLA without an obvious source [32].

Mortality rates from PLA have declined over time [5, 33]. Recent retrospective studies report mortalities between 0 and 13\%, although length of follow up varies and often only in-hospital mortality is reported [1, 15, 34-40]. The 30-day and 6 month mortality rates in our cohort were 5.3 and $15.2 \%$ respectively, which are similar to outcomes in other units. Numerous studies have attempted to describe predictors of mortality in PLA; advanced age, leucocytosis, hyperbilirubinaemia, underlying malignancy, biliary aetiology, diabetes, abscess diameter $\geq 5 \mathrm{~cm}$ and underlying organism have all been suggested as risk factors [5, 22, 41-47]. In our study, only baseline ALP and the presence of loculation were predictive of mortality.

Along with antibiotic therapy, options for treatment of PLA include percutaneous aspiration, percutaneous drainage and open surgical drainage. There have been no trials that have compared these different treatment strategies. In our group, $60 \%$ of cases were managed with aspiration or drainage in addition to antibiotic therapy $(76.3 \%$ of large $(>5 \mathrm{~cm})$ abscesses vs. $25 \%$ of small $(<5 \mathrm{~cm})$ abscesses). Seven (5.3\%) of our PLAs required surgical drainage. It is unclear how percutaneous or surgical drainage affected outcomes. Antibiotic treatment was altered at least once in $79.5 \%$ of PLA patients (more than twice in $34.1 \%$ ), some due to antibiotic resistance, with $34.1 \%$ of patients growing a resistant organisms, including $12.1 \%$ resistance to one of the most commonly used empiric antibiotic, co-amoxiclav, but others will have been altered empirically due to deterioration of the patient. This observation underlines the importance of early pathogen identification in order to optimise management.

\section{Conclusions}

There is little quality evidence to guide optimal management of PLA. Using a well-characterised cohort of liver abscess patients, we found some correlations between organism, clinical features and outcomes of treatment. The heterogeneity of this cohort of liver abscesses, as with others in the literature, means that associations may have been missed and that those identified, such as higher CRP in ALAs and larger size in PLAs caused by streptococci, are too subtle to be of use to clinicians. These findings emphasise the need for a microbiological diagnosis, which is most effectively obtained by culture of aspirate fluid. We found $16 \mathrm{~s}$ rRNA gene PCR useful in the identification of bacteria in culture negative samples. Newer molecular technologies such highthroughput sequencing may, in the future, further improve the sensitivity of nucleic acid amplification tests and may also provide antibiotic susceptibility data and this is likely to lead to improved outcomes for individuals with these infections.

\section{Additional file}

Additional file 1: 4 tables showing additional supporting statistical analysis of data described in main manuscript. (DOCX $30 \mathrm{~kb}$ ) 


\section{Abbreviations}

ALA: Amoebic liver abscess; ALP: Alkaline phosphatase; ALT: Alanine transferase; BSAC: British Society of Antimicrobial Chemotherapy; CAP: Cellulose Acetate Precipitin; CPA: Clinical Pathology Accreditation; EUCAST: European Committee on Antimicrobial Susceptibility Testing; IFAT: Immunofluorescent antibody test; PLA: Pyogenic liver abscess; rRNA: Ribosomal RNA

\section{Authors' contributions}

AMcG and DH planned and designed the study, with advice from GGR. LN, FE and DW collected and prepared the data. SMC performed the analyses. $\mathrm{DH}$ and LN performed the literature search. All authors were involved in interpretation of results, drafting and revision of the manuscript, and approved the final version.

\section{Funding}

This study did not receive funding.

\section{Availability of data and materials}

The data on which this study was based can be made available by the corresponding author to bone fide researchers subject to appropriate ethical approvals.

\section{Ethics approval and consent to participate}

Our work was done as part of a clinical audit of service delivery on pseudonymised data supplied by clinical coding and from an internal database and ethical approval was not required.

\section{Consent for publication}

Not applicable.

\section{Competing interests}

The authors declare that they have no competing interests.

\section{Author details}

${ }^{1}$ Department of Infectious Diseases and Tropical Medicine, London North West Healthcare NHS Trust, Northwick Park Hospital, Middlesex, Harrow HA1 3UJ, UK. ${ }^{2}$ Healthcare-Associated Infection \& Antimicrobial Resistance Division, National Infection Service, Public Health England, 61 Colindale Avenue, London NW9 5EQ, UK. ${ }^{3}$ Department of Microbiology, London North West Healthcare NHS Trust, Northwick Park Hospital, Middlesex, Harrow HA1 3UJ, UK. ${ }^{4}$ Department of Medicine, Imperial College London, London, UK.

\section{Received: 13 February 2019 Accepted: 23 May 2019}

\section{Published online: 03 June 2019}

\section{References}

1. Lo JZ, Leow LJ, Ng PL, Lee HQ, Mohd Noor NA, Low JK. Predictors of therapy failure in a series of 741 adult pyogenic liver abscesses. J Hepatobiliary Pancreat Sci. 2015;22(2):156-65.

2. Tsai FC, Huang Y, Chang LY, Wang JT. Pyogenic liver abscess as endemic disease, Taiwan. Emerg Infect Dis. 2008;14(10):1592-600.

3. Jepsen $\mathrm{P}$, Vilstrup $\mathrm{H}$, Schonheyder HC, Sorensen HT. A nationwide study of the incidence and 30-day mortality rate of pyogenic liver abscess in Denmark, 1977-2002. Aliment Pharmacol Ther. 2005;21(10):1185-8.

4. Meddings L, Myers R, Hubbard J, Shaheen AA, Laupland KB, Dixon E, Coffin C, Kaplan GG. A population-based study of pyogenic liver abscesses in the United States: incidence, mortality, and temporal trends. Am J Gastroenterol. 2010;105(1):117-24

5. Huang CJ, Pitt HA, Lipsett PA, Osterman FA, Lillemoe K, Cameron JL, Zuidema GD. Pyogenic hepatic abscess: changing trends over 42 years. Ann Surg. 1996;223(5):600-9.

6. Rahiman J, Wilson T, Oram V, Holzman RS. Pyogenic liver abscess: recent trends in etiology and mortality. Clin Infect Dis. 2004;39(11):1654-9.

7. Menon AR, Kizhakkekarammal PK, Rao GK. Amoebic vs pyogenic liver abscesses: a comparative study in a tertiary care hospital. J Academy Clin Microbiol. 2015;17(2):89-93.

8. Stanley SL. Amoebiasis. Lancet. 2003;361(9362):1025-34

9. Barnes PF, De Cock KM, Reynolds TN, Ralls PW. A comparison of amebic and pyogenic abscess of the liver. Medicine (Baltimore). 1987;66(6):472-83.
10. Lodhi S, Sarwari AR, Muzammil M, Salam A, Smego RA. Features distinguishing amoebic from pyogenic liver abscess: a review of 577 adult cases. Tropical Med Int Health. 2004;9(6):718-23.

11. Cosme A, Ojeda E, Zamarreño I, Bujanda L, Garmendia G, Echeverría MJ, Benavente J. Pyogenic versus amoebic liver abscesses. A comparative clinical study in a series of 58 patients. Rev Esp Enferm Dig. 2010;102(2):90-9.

12. Conter RL, Pitt HA, Tompkins RK, Longmire WP. Differentiation of pyogenic from amebic hepatic abscesses. Surg Gynecol Obstet. 1986;162(2):114-20.

13. Mohsen AH, Green ST, Read RC, McKendrick MW. Liver abscess in adults: ten years experience in a UK centre. QJM. 2002;95(12):797-802.

14. Lee KT, Wong SR, Sheen PC. Pyogenic liver abscess: an audit of 10 years' experience and analysis of risk factors. Dig Surg. 2001;18(6):459-65 discussion 65-6.

15. Pang TC, Fung T, Samra J, Hugh TJ, Smith RC. Pyogenic liver abscess: an audit of 10 years' experience. World J Gastroenterol. 2011;17(12):1622-30.

16. Bosanko NC, Chauhan A, Brookes M, Moss M, Wilson PG. Presentations of pyogenic liver abscess in one UK centre over a 15-year period. J R Coll Physicians Edinb. 2011:41:13-7.

17. Petri A, Hohn J, Hódi Z, Wolfárd A, Balogh A. Pyogenic liver abscess -- 20 years' experience. Comparison of results of treatment in two periods. Langenbeck's Arch Surg. 2002;387:27-31.

18. Abbas MT, Khan FY, Muhsin SA, Al-Dehwe B, Abukamar M, Elzouki AN. Epidemiology, clinical features and outcome of liver abscess: a single reference center experience in Qatar. Oman Med J. 2014;29(4):260-3.

19. Pritt BS, Clark CG. Amebiasis. Mayo Clin Proc. 2008;83(10):1154-9 quiz 9-60.

20. Ralls PW, Barnes PF, Radin DR, Colletti P, Halls J. Sonographic features of amebic and pyogenic liver abscesses: a blinded comparison. AJR Am J Roentgenol. 1987;149(3):499-501.

21. Chen SC, Huang C, Tsai SJ, Yen CH, Lin DB, Wang PH, Chen CC, Lee MC. Severity of disease as main predictor for mortality in patients with pyogenic liver abscess. Am J Surg. 2009;198(2):164-72.

22. Alvarez Pérez JA, Gonzalez JJ, Baldonedo RF, Sanz L, Carreño G, Junco A, Rodriguez Jl, Martinez MD, Jorge Jl. Clinical course, treatment, and multivariate analysis of risk factors for pyogenic liver abscess. Am J Surg. 2001:181:177-86.

23. Huse SM, Ye Y, Zhou Y, Fodor AA. A core human microbiome as viewed through 16S rRNA sequence clusters. PLoS One. 2012;7(6):e34242.

24. Song YG, Shim SG, Kim KM, Lee DH, Kim DS, Choi SH, Song JY, Kang HL, Baik SC, Lee WK, Cho MJ, Rhee KH. Profiling of the bacteria responsible for pyogenic liver abscess by 165 rRNA gene pyrosequencing. J Microbiol. 2014; 52(6):504-9.

25. Sibley CD, Church D, Surette MG, Dowd SE, Parkins MD. Pyrosequencing reveals the complex polymicrobial nature of invasive pyogenic infections: microbial constituents of empyema, liver abscess, and intracerebral abscess. Eur J Clin Microbiol Infect Dis. 2012;31:2679-91.

26. Krige JE, Beckingham IJ. ABC of diseases of liver, pancreas, and biliary system. BMJ. 2001;322(7285):537-40.

27. Tsai MS, Lee HM, Hsin MC, Lin CL, Hsu CY, Liu YT, Kao CH. Increased risk of pyogenic liver abscess among patients with colonic diverticular diseases: a Nationwide cohort study. Medicine (Baltimore). 2015:94(49):e2210.

28. Mavilia MG, Molina M, Wu GY. The evolving nature of hepatic abscess: a review. J Clin Transl Hepatol. 2016:4(2):158-68.

29. Thomsen RW, Jepsen P, Sorensen HT. Diabetes mellitus and pyogenic liver abscess: risk and prognosis. Clin Infect Dis. 2007:44(9):1194-201.

30. Foo NP, Chen KT, Lin HJ, Guo HR. Characteristics of pyogenic liver abscess patients with and without diabetes mellitus. Am J Gastroenterol. 2010;105(2):328-35.

31. Chuah SK, Chang-Chien C, Sheen IS, Lin HH, Chiou SS, Chiu CT, Kuo CH, Chen JJ, Chiu KW. The prognostic factors of severe amebic liver abscess: a retrospective study of 125 cases. Am J Trop Med Hyg. 1992:46(4):398-402.

32. Jeong SW, Jang JY, Lee TH, Kim HG, Hong SW, Park SH, Kim SG, Cheon YK, Kim YS, Cho YD, Kim JO, Kim BS, Lee EJ, Kim TH. Cryptogenic pyogenic liver abscess as the herald of colon cancer. J Gastroenterol Hepatol. 2012;27:248-55.

33. Farges $\mathrm{O}$, Leese $\mathrm{T}$, Bismuth $\mathrm{PH}$. Pyogenic liver abscess: an improvement in prognosis. Br J Surg. 1988;75(9):862-5

34. Du ZQ, Zhang L, Lu Q, Ren YF, Lv Y, Liu XM, Zhang XF. Clinical characteristics and outcome of pyogenic liver abscess with different size: 15-year experience from a single center. Sci Rep. 2016:6:35890.

35. Heneghan HM, Healy NA, Martin ST, Ryan RS, Nolan N, Traynor O, Waldron R. Modern management of pyogenic hepatic abscess: a case series and review of the literature. BMC Res Notes. 2011;4(1):80. 
36. Su YJ, Lai YC, Lin YC, Yeh YH. Treatment and prognosis of pyogenic liver abscess. Int J Emerg Med. 2010;3(4):381-4.

37. O'Farrell N, Collins CG, McEntee GP. Pyogenic liver abscesses: diminished role for operative treatment. Surgeon. 2010;8(4):192-6.

38. Czerwonko ME, Huespe P, Bertone S, Pellegrini P, Mazza O, Pekolj J, de Santibañes E. Pyogenic liver abscess: current status and predictive factors for recurrence and mortality of first episodes. HPB. 2016;8(12):1023-30.

39. Zhu X, Wang S, Jacob R, Fan Z, Zhang F, Ji G. A 10-year retrospective analysis of clinical profiles, laboratory characteristics and Management of Pyogenic Liver Abscesses in a Chinese hospital. Gut Liver. 2011;5(2):221-7.

40. Santos-Rosa OM, Lunardelli H, Ribeiro-Junior MAF. Pyogenic liver abscess: diagnostic and therapeutic management. Arg Bras Cir Dig. 2016;29(3):194-7.

41. Chen $\mathrm{CH}$, Wu SS, Chang HC, Chang YJ. Initial presentations and final outcomes of primary pyogenic liver abscess: a cross-sectional study. BMC Gastroenterol. 2014;41(1):133

42. Chen SC, Tsai SJ, Chen CH, Huang CC, Lin DB, Wang PH, Chen CC, Lee MC. Predictors of mortality in patients with pyogenic liver abscess. Neth J Med. 2008;66:196-203.

43. Chen $\mathrm{WH}$, Chiu $\mathrm{CH}$, Huang $\mathrm{CH}$, Lin $\mathrm{CH}$, Sun JH, Huang YY, Wang $\mathrm{CC}$ Pyogenic liver abscess caused by pseudomonas aeringosa: clinical analysis of 20 cases. Scand J Infect Dis. 2011;43(11-12):877-82.

44. Chou FF, Sheen-Chen SM, Chen YS, Chen MC, Chen FC, Tai DI. Prognostic factors for pyogenic abscess of the liver. J Am Coll Surg. 1994;179:727-32.

45. Lee KT, Sheen PC, Chen JS, Ker CG. Pyogenic liver abscess: multivariate analysis of risk factors. World J Surg. 1991;15(3):372-6.

46. Mischinger $\mathrm{HJ}$, Hauser $\mathrm{H}$, Rabl H, Quehenberger F, Werkgartner G, Rubin R Due E. Pyogenic liver abscess: studies of therapy and analysis of risk factors. World J Surg. 1994;18:852-7.

47. Yeh TS, Jan YY, Jeng LB, Hwang TL, Chao TC, Chien RN, Chen MF. Pyogenic liver abscesses in patients with malignant disease: a report of 52 cases treated at a single institution. Arch Surg. 1998;133(3):242-5.

\section{Publisher's Note}

Springer Nature remains neutral with regard to jurisdictional claims in published maps and institutional affiliations.

Ready to submit your research? Choose BMC and benefit from:

- fast, convenient online submission

- thorough peer review by experienced researchers in your field

- rapid publication on acceptance

- support for research data, including large and complex data types

- gold Open Access which fosters wider collaboration and increased citations

- maximum visibility for your research: over $100 \mathrm{M}$ website views per year

At $\mathrm{BMC}$, research is always in progress.

Learn more biomedcentral.com/submissions 